\title{
LETTERS
}

\section{Trends in the Management of Headache}

\author{
Glen D. Solomon, M.D., F.A.C.P. \\ Boonshoft School of Medicine, Wright State University, Dayton, OH, USA.
}

$\mathrm{J}$ Gen Intern Med 30(6):710

DOI: $10.1007 / \mathrm{s} 11606-015-3224-7$

(C) Society of General Internal Medicine 2015

$\mathrm{T}$ o the Editors - I read with great interest the article on "Trends in the Ambulatory Management of Headache"1 reporting a decline in clinician counseling for headache. While the paper references three clinical guidelines ${ }^{2-4}$ suggesting lifestyle modification counseling during headache visits, a review of those guidelines shows no evidence to support lifestyle counseling as having efficacy in reducing migraine or headarche frequency. Review of the headache literature also fails to show scientific evidence that lifestyle modification - changes in diet, sleep, or exercise - have ever been proven to reduce headache frequency.

Lifestyle modification counseling may provide value in specific situations. There is evidence that simple advice can be effective as a withdrawal strategy in medication overuse headache. ${ }^{5}$ Obesity and smoking have been associated with increased severity of headaches, in addition to other myriad medical problems, and should be discouraged.

Physicians have limited time with headache patients to take a detailed history, perform an appropriate physical examination, review the diagnosis and treatment options, and explore patient preferences for therapy. Using that limited time for lifestyle modification counseling that provides no clinical benefit offers no value.

As a headache specialist for over 30 years, I find that I spend increasing amounts of patient time debunking myths about the value of lifestyle modification. While increased stress, dehydration, lack of sleep, sedentary lifestyle, and poor diet all may contribute to poor health, they have not been scientifically linked to increased migraine frequency. Emphasis on lifestyle modification may detract from nonpharmacologic therapies that have evidence to support their use in headache, such as biofeedback, relaxation therapy, and cognitive-behavioral therapy. ${ }^{2}$

While I find it discouraging that the use of advanced imaging and referrals have increased for headache patients, I do not believe that the decline in lifestyle modification counseling reflects a lost opportunity to improve the value of healthcare.

Corresponding Author: Glen D. Solomon, M.D., F.A.C.P.; Boonshoft School of Medicine Wright State University, PO Box 927, Dayton, OH 45401-0927, USA (e-mail: Glen.solomon@wright.edu).

\section{REFERENCES}

1. Mafi JN, Edwards ST, Pedersen NP, davis RB, McCarthy EP, Landon BE. Trends in the Ambulatory Management of Headache: Analysis of NAMCS and NHAMCS Data 1999-2010. J Gen Intern Med. doi:10.1007/s11606014-3107-3.

2. Silberstien SD. Practice parameter: Evidence-based guidelines for migraine headache (an evidence-based review): Report of the Quality Standards subcommittee of the American Academy of Neurology. Neurology. 2000;55(6):754-762.

3. Snow V, Weiss $\mathbf{K}$, Wall EM. Guidelines for the treatment and prevention of migraine headaches. Ann Intern Med. 2002;137(10):840-852.

4. Belthon J, Galtenberg M, Johnson K, Kildahl P, Krenik J, Liebow M, et al. Institute for clinical systems improvement. Diagnosis and treatment of headache. https://www.iest.org/-asset/qwrznq/Headache.pdf August 1998 (Revised January 2013).

5. Rossi P, Faroni JV, Nappi G. Short-term effectiveness of simple advice as a withdrawal strategy in simple and complicated medication overuse headache. Eur J Neurol. 2011;18:396-401. 